\title{
Use of Complementary and Alternative Medicine (CAM) and Home Remedies by COVID-19 Patients: A Telephonic Survey
}

\author{
Jaykaran Charan ${ }^{1} \cdot$ Pankaj Bhardwaj $^{2} \cdot$ Siddhartha Dutta $^{1} \cdot$ Rimplejeet Kaur $^{3}$ (ID $\cdot$

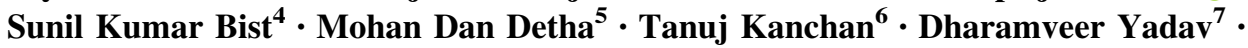 \\ Prasenjit Mitra $^{7} \cdot$ Praveen Sharma $^{7}$
}

Received: 13 September 2020/Accepted: 20 October 2020/Published online: 31 October 2020

(C) Association of Clinical Biochemists of India 2020

\begin{abstract}
COVID-19 is caused by a novel coronavirus which was first reported in Wuhan city, China. The pandemic has led to considerable mortality globally. India, at present has the second largest burden of COVID-19 cases globally. Clinical trials with new interventions, including new vaccine candidates are being explored in the scientific world. Countries like China and India, with a rich history of traditional medicine, are exploring the effectiveness of traditional medicines to treat COVID-19. This study included 725 patients from an Isolation center, of which $230(31.7 \%)$ were excluded due to reasons like incorrect phone numbers, no response on phone, or denying consent to participate. Finally, 495 participants had responded, of which $367(74.1 \%)$ had not used any Complementary and Alternative Medicine (CAM) product or home remedies while $128(25.8 \%)$ people used 161 CAM products and
\end{abstract}

Rimplejeet Kaur

sidhurimple@yahoo.com

1 Department of Pharmacology, All India Institute of Medical Sciences, Jodhpur, Rajasthan, India

2 Department of Community and Family Medicine, All India Institute of Medical Sciences (AIIMS), Jodhpur, Rajasthan, India

3 Department of Pharmacology, Dr. S.N Medical College, Jodhpur, Rajasthan, India

4 Medical and Health, Jodhpur Zone and COVID 19 Nodal Officer, Jodhpur, Rajasthan, India

5 Block CMHO, Luni, Jodhpur and Medical Officer Incharge, COVID Care Centre, Boranda, Jodhpur, Raj, India

6 Department of Forensic Medicine, All India Institute of Medical Sciences, Jodhpur, Rajasthan, India

7 Department of Biochemistry, All India Institute of Medical Sciences, Jodhpur, Rajasthan, India home remedies during the treatment and even afterward. More than half of the participants (59.6\%) among them had consumed Ayurvedic Kadha. Many respondents consumed more than one CAM products or home remedies but there were no reported acute or severe adverse effects with these products. However, it is essential to ensure the safety of these interventions on long-term use because patients with other comorbidities can have a detrimental effect due to these products or due to drug herb interaction with their ongoing medications. Hence, long-term follow-up studies of recovered patients are crucial in determining the effects of medications or CAM products on organ functions due to disease or interventions.

Keywords CAM - Complimentary alternative medicine . COVID-19

\section{Introduction}

The Coronavirus disease 2019 (COVID-19) which is caused by novel coronavirus or severe acute respiratory syndrome coronavirus 2 (SARS-CoV-2) was first reported in the Wuhan city of China in December 2019 [1]. The current pandemic of COVID-19 has affected the entire world and led to considerable morbidity and mortality. India is seeing a continuous rise in the number of cases with no sign of flattening of the curve and as of 17 th September 2020, with 5,118,253 confirmed cases and 83,198 deaths currently stands second in the maximum number of cases in the entire world [2,3]. The Indian healthcare system, currently has been under constant pressure because of the diverse challenges posed by Covid19. Enormous efforts are being taken by Governments, health care professionals, and pharmaceutical companies to 
contain this disease across the world. Currently, we do not have any approved drug or vaccine candidate for the treatment of COVID-19 but continuous efforts are being made by the scientific world by conducting clinical trials with new interventions, including new vaccines candidates are being explored [4]. Countries like China and India, with a rich history of traditional medicine, are exploring the effectiveness of their traditional medicines to treat COVID19.

The Ministry of AYUSH (Ayurveda, Yoga, and Naturopathy, Unani, Siddha, and Homeopathy), Government of India (GoI), with the objective of developing an intervention to prevent or cure COVID-19 by using concepts of AYUSH established an interdisciplinary AYUSH research and development task force and guidelines for AYUSH clinical studies in COVID-19 to encourage research and generation of evidence of various traditional drugs on COVID-19 [5]. The guidance document also mentions that AYUSH interventions have a multi-targeted treatment approach and might demonstrate beneficial effects as prophylaxis, treatment, or management of cases in the recovery stage. The interventions can help to treat the patients as an add-on to the standard of care drugs or can also prove to be a stand-alone treatment. The task force planned to focus on the multi-pronged approach of Ayurvedic medicines which are already in use for decades for various ailments like fever, cough, and respiratory distress along with improving their immunity and assisting it with proper diet. Evidence shows that several plant products or extracts and spices some of which are commonly used like pepper, ginger, cumin, and coriander seeds are also used in ayurvedic preparation and shown to have anti-viral, anti-bacterial, and anti-microbial properties [5-8].

Ministry of AYUSH in India is guiding different trials of herbal medicines which have been used safely for other ailments, for prophylaxis or treatment of COVID-19, and of all the COVID-19 related clinical trials registered in the Clinical Trial Registry of India (CTRI), about 60\% are related to the AYUSH interventions [9]. Likewise, at the same time, many preparations particularly from Complementary and Alternative Medicines (CAM) are being propagated without having any scientific evidence. India as a country has immense belief in their traditional medicines and household treatment strategies. Given that, some of these preparations lack available data related to the efficacy, adverse events, manufacturing method, and quality control. Their easy availability and advertising have led to their un-supervised use in society. Hence, the present study was planned to know the pattern and frequency of the use of CAM products and other home remedies among asymptomatic COVID-19 patients.

This study was conducted at an Isolation center, where asymptomatic COVID-19 patients were admitted for
10 days as per the State Health policy of the Government of Rajasthan, India. These patients were discharged after 10 days of admission if no symptoms developed during their stay. Symptomatic patients, pregnant women, patients with comorbidity, or age more than 60 years were transferred to the dedicated COVID-19 Hospitals. The data of the isolated patients were extracted from the isolation center which contained all basic demographic details along with their contact numbers. Two trained researchers contacted these patients on the telephone and asked about the use of any CAM product or home remedies before, during, or after the discharge from the isolation Center after obtaining verbal informed consent from the participants. They were made to understand that participation in the survey is completely voluntary. The timing of this telephonic interview was between one to two months after the discharge of such patients. Responses were analyzed using SPSS version 21. Descriptive statistics were used in the form of frequency and percentages.

Out of the 725 patients of the Isolation center, information regarding the use of CAM and home remedies could not be obtained from $230(31.7 \%)$ individuals due to incorrect phone numbers, non-responses over the phone, or denying consent to participate in the study. Out of the 495 participants who responded, $367(74.1 \%)$ have not used any CAM product or home remedies while 128 (25.8\%) people used $161 \mathrm{CAM}$ products and home remedies during the treatment and afterward, as shown in Table 1. Results of the present study show that more than half of the participants who used CAM product or home remedies had consumed Ayurvedic Kadha (59.6\%), which is an ayurvedic drink prepared by extraction of various herbs. Many respondents consumed more than one CAM product or home remedies (Table 1). None of the respondents were aware of necessary details like the brand or manufacturer of such preparations. Most of the respondents confirmed taking household preparations of herbs. Literature shows that the virus has its effect on the immune system of our body hence having a strong immune system is crucial in the prevention of various viral infections [10]. Evidence also suggests CAM products are effective in boosting immune response. The herbs and plant products that are consumed daily in our diet in India like Curcumin has been found to boost immunity and also has antiviral properties by acting on the inflammatory medications and messengers [11-14]. There is also evidence that multivitamins, herbs, and nutritional supplements that are present in CAM products can also help in boosting immunity and protecting us from infections [15]. The finding of use of herbs in India in COVID-19 patients is supported by evidence reported by Luo et al. from China where they reported multiple herbs being used for management of COVID-19 patients [16]. AYUSH Ministry, GoI also in their 'Self-care guidelines 
Table 1 Use of CAM preparations by asymptomatic COVID 19 patients $(\mathrm{n}=161)$

\begin{tabular}{lr}
\hline Complementary and alternative medicine $(\mathrm{CAM})$ and other home remedies & $\mathrm{N}(\%)$ \\
\hline Ayurvedic Kadha & $96(59.6)$ \\
Giloy & $31(19.2)$ \\
Tulsi & $24(14.9)$ \\
Amla & $6(3.7)$ \\
Turmeric & $3(1.8)$ \\
Ashvgandha & $1(0.6)$ \\
Coronil & $1(0.6)$ \\
\hline
\end{tabular}

$N$ Number of patients for preventive health measures and immunity-boosting with special reference to respiratory health' recommends having spices like Haldi (Turmeric), Jeera (Cumin), Dhaniya (Coriander), and Lahsun (Garlic) while cooking and drinking herbal tea or Kadha added with Tulsi (Basil), Dalchini (Cinnamon), Kalimirch (Black pepper), Shunthi (Dry Ginger) and Munakka (Raisin) [17].

In the current study, none of the participants reported any acute or severe side effects while consuming these herbal products. However, it needs to be seen if there are any associated long-term harmful effects of these interventions. At present, the herbal drugs which are being explored or tested are being used in India for years and have been seen to cure various ailments of the people but there was no systematic monitoring or documentation of expected or unexpected adverse events associated with these agents. Using herbal agents with allopathic drugs that are given as a standard of care can sometimes lead to the development of unexpected adverse events due to unknown drug herb interaction and worsen the condition of the patients. It is suggested that proper monitoring of the patients should be done and laboratory tests should be conducted for assessing any short/ long-term organ damage particularly liver and kidney dysfunctions. Evidence shows that the COVID-19 per se may itself causes liver/kidney dysfunctions [18]. Hence there is a possibility that the interventions used for the prophylaxis and treatment of COVID-19 can further compromise the liver and kidney functions which need to be further explored. Therefore, long-term follow-up studies of recovered patients should be planned to assess any derangement in organ functions due to disease or interventions.

\section{References}

1. World Health Organization. Naming the coronavirus disease (COVID-19) and the virus that causes it. https://www.who.int/ emergencies/diseases/novel-coronavirus-2019/technical-gui dance/naming-the-coronavirus-disease-(covid-2019)-and-thevirus-that-causes-it. Accessed 16 Sep 2020.
2. Mitra P, Misra S, Sharma P. COVID-19 pandemic in India: what lies ahead. Ind J Clin Biochem. 2020;35:257-9.

3. World Health Organization. Coronavirus Disease (COVID-19) Dashboard. https://covid19.who.int/region/searo/country/in. Accessed 18 Sep 2020.

4. Coronavirus research publishing: The rise and rise of COVID-19 clinical trials [Internet]. Natureindex.com. 2020 https://www.nat ureindex.com/news-blog/the-top-coronavirus-research-articlesby-metrics. Accessed 18 Sep 2020.

5. Interdisciplinary AYUSH Research \& Development Task Force. Ministry of AYUSH, Government of India. https://www.ayush. gov.in/docs/clinical-protocol-guideline.pdf. Accessed 16 Sep 2020.

6. Ogbole OO, Akinleye TE, Segun PA, Faleye TC, Adeniji AJ. In vitro antiviral activity of twenty-seven medicinal plant extracts from Southwest Nigeria against three serotypes of echoviruses. Virol J. 2018;15:110. https://doi.org/10.1186/s12985-018-1022-7.

7. Pushpa R, Navin N, Pankaj G. Antiviral potential of medicinal plants: an overview. Intl Res J Pharm. 2013;4(6):8-16. https:// doi.org/10.7897/2230-8407.04603.

8. Akram M, Tahir IM, Shah SMA, Mahmood Z, Altaf A, Ahmad $\mathrm{K}$, et al. Antiviral potential of medicinal plants against HIV, HSV, influenza, hepatitis, and coxsackievirus: a systematic review. Phytother Res. 2018;32(5):811-22. https://doi.org/10. 1002/ptr.6024.

9. Charan J, Kaur R, Bhardwaj P, et al. Snapshot of COVID-19 related clinical trials in India. Ind J Clin Biochem. 2020. https:// doi.org/10.1007/s12291-020-00918-1.

10. Notkins AL, Mergenhagen SE, Howard R. Effect of virus infections on the function of the immune system. Annu Rev Microbiol. 1970;24(1):525-38.

11. Richart SM. Synergic effect of curcumin and its structural analogue (Monoacetylcurcumin) on anti-influenza virus infection. J Food Drug Anal. 2018;26(3):1015-23.

12. Jagetia GC, Aggarwal BB. "Spicing up" of the immune system by curcumin. J ClinImmunol. 2007;27(1):19-35.

13. Ranjan D. Curcumin inhibits mitogen stimulated lymphocyte proliferation, NFKB activation, and IL-2 signaling. J Surg Res. 2004;121(2):171-7.

14. Mathew D, Hsu W-L. Antiviral potential of curcumin. J Funct Foods. 2018;40:692-9.

15. Nilashi M, Samad S, Yusuf SYM, Akbari E. Can complementary and alternative medicines be beneficial in the treatment of COVID-19 through improving immune system function? J Infect Public Health. 2020;13(6):893-6. https://doi.org/10.1016/j.jiph. 2020.05.009.

16. Luo H, Tang QL, Shang YX, Liang SB, Yang M, Robinson N, Liu JP. Can Chinese medicine be used for prevention of corona virus disease 2019 (COVID-19)? A review of historical classics, research evidence and current prevention programs. Chin J Integr 
Med. 2020;26(4):243-50. https://doi.org/10.1007/s11655-0203192-6.

17. Ayurveda's immunity boosting measures for self-care during COVID 19 crisis. Ministry of AYUSH, Government of India. https://www.ayush.gov.in/. Accessed 18 Sep 2020.

18. Fan Z, Chen L, Li J, Xi C, Yang J, Tian C. Clinical features of COVID-19-related liver functional abnormality. ClinGastroenterolHepatol. 2020;18:1561-6.
Publisher's Note Springer Nature remains neutral with regard to jurisdictional claims in published maps and institutional affiliations. 